\title{
Welfarism, Preferencism, Judgmentism
}

Citation for published version (APA):

Dietrich, F. K. (2006). Welfarism, Preferencism, Judgmentism. Maastricht University School of Business and Economics. METEOR Research Memorandum No. 005 https://doi.org/10.26481/umamet.2006005

Document status and date:

Published: 01/01/2006

DOI:

10.26481/umamet.2006005

Document Version:

Publisher's PDF, also known as Version of record

\section{Please check the document version of this publication:}

- A submitted manuscript is the version of the article upon submission and before peer-review. There can be important differences between the submitted version and the official published version of record.

People interested in the research are advised to contact the author for the final version of the publication, or visit the DOI to the publisher's website.

- The final author version and the galley proof are versions of the publication after peer review.

- The final published version features the final layout of the paper including the volume, issue and page numbers.

Link to publication

\footnotetext{
General rights rights.

- You may freely distribute the URL identifying the publication in the public portal. please follow below link for the End User Agreement:

www.umlib.nl/taverne-license

Take down policy

If you believe that this document breaches copyright please contact us at:

repository@maastrichtuniversity.nl

providing details and we will investigate your claim.
}

Copyright and moral rights for the publications made accessible in the public portal are retained by the authors and/or other copyright owners and it is a condition of accessing publications that users recognise and abide by the legal requirements associated with these

- Users may download and print one copy of any publication from the public portal for the purpose of private study or research.

- You may not further distribute the material or use it for any profit-making activity or commercial gain

If the publication is distributed under the terms of Article $25 \mathrm{fa}$ of the Dutch Copyright Act, indicated by the "Taverne" license above, 


\title{
Welfarism, preferencism, judgmentism
}

\author{
Franz Dietrich, University of Maastricht \\ January 2006
}

\begin{abstract}
In a single framework, I address the question of the informational basis for evaluating social states. I particularly focus on information about individual welfare, individual preferences and individual (moral) judgments, but the model is also open to any other informational input deemed relevant, e.g. sources of welfare and motivations behind preferences. In addition to proving some possibility and impossibility results, I discuss objections against using information about only one aspect (e.g. using only preference information). These objections suggest a multi-aspect informational basis for aggregation. However, the multi-aspect approach faces an impossibility result created by a lack of inter-aspect comparability. The impossibility could be overcome by measuring information on non-cardinal scales.
\end{abstract}

\section{Introduction}

Welfare economics studies ways to evaluate the goodness of social states. Two central and largely controversial issues are: On what information should the evaluation of social states depend? How should this evaluation (functionally) depend on the information? This paper is concerned with the first question. This question of the informational basis has so far mainly been debated informally or analysed philosophically. For instance, the interpretational difference between aggregating people's interests and aggregating people's opinions is at the heart of Sen (1970a) and fills the first lines in Roberts (1995). I will put the question of informational input on a more formal basis, and address both conceptual and technical aspects.

Much of the interest that the question of the informational basis is receiving relates to the debate over welfarism, the position that all that is needed to rank two social states is the information of each person's welfare in each state (where welfare is seen as a single real number, yet possibly affected by various factors such as happiness, freedom, health, etc.). To illustrate the welfarism debate, let me recall a pleasant highlight of the Seventh International Meeting of the Society for Social Choice and Welfare (Osaka, 2004). After Charles Blackorby had finished his Arrow Lecture, the discussion begun, not surprisingly, with an intervention of Amartya Sen, who challenged the welfarist position by contrasting two social states, the first of which seemed intuitively better despite of giving 
each person lower welfare. Specifically, the first society is one of harmony, freedom and happiness, giving each person welfare 100. The second society gives everyone the even higher welfare of 101, but achieves this through arguably repulsive means: people are connected to Robert Nozick's "experience machine", which gives them permanent pleasurable brain stimuli. Blackorby replied by arguing that Sen's story is inconsistent: if the second society is really repulsive, this should be reflected in lower welfare levels; conversely, if people's welfare in the second society is really as high as 101, it would be "paternalistic" to rank the first society higher.

Suppose the welfare levels specified by Sen are correct. Would it then really be paternalist to consider the first society better? An answer, it seems, would require more information: how much do people want each society (preference information), and how socially good do people themselves judge each society to be (judgment information)? In Sen's story, like in the standard model of welfare economics more generally, only individual welfare levels are explicitly quantified. Other information, such as preference information, judgment information, and source-of-welfare information, are not explicitly modelled. The approach of this paper is to make explicit and quantify all information deemed relevant. The problem of the potential meaninglessness or practical infeasibility of such measurements is of course serious, but it can be accounted for by imposing suitable invariance conditions on aggregation.

Specifically, I propose to consider a set of relevant issues (Sam's welfare, Ann's source of welfare, Peter's preference, Daniel's freedom, whether Peter's preference meddles into Daniel's freedom, the preservation of nature, etc.), and to each issue a performance function that measures how well each state performs on the issue. I will consider the aggregation problem of aggregating these performance functions into a social betterness ordering. In this framework, I will formulate and analyse different informational restrictions: welfarism, preferencism, and judgmentism, which require the ranking of two states to be given solely by the performances on the issues of, respectively, people's welfares, people's preferences, and people's goodness judgments. These three informational bases are fundamentally distinct from each other: someone can get welfare from a state without wanting it (e.g. if her preferences are other-regarding), or want a state without judging it is socially good (e.g. if her preferences are selfinterested), or get welfare from a state without judging it as good (e.g. if she is the winner of a redistribution she considers unfair). I will argue that welfarism faces a paternalism charge, that preferencism potentially favours selfish people, and that the relevance of judgment information hinges on the interpretation given to aggregation. I will prove a theorem similar to the welfarism theorem, but for an arbitrary (sub)set of issues rather than for welfare issues. Given the objections against "single-aspect" approaches such as welfarism, preferencism or judgmentism, I will investigate the potential of a "multi-aspect" approach that combines information of different kinds. The main problem is that sufficiently different aspects are arguably non-comparable. This will lead us to an impos- 
sibility result in the spirit to Arrow's Theorem, and closely related to results derived in different contexts by Roberts (1995), Khmelnitskaya and Weymark (2000), and List (2004). I will argue that the inter-aspect non-comparability can usually not be overcome, as inter-aspect comparisons are not just difficult to implement but usually meaningless. So, the multi-aspect approach can (and should) arguably be rescued by allowing forms of measurability other than cardinal measurability.

\section{A general aggregation problem}

We consider a set $X$ of (social) states with $|X| \geq 3$. On the basis of what information should $X$ be ranked? Most current formal work in welfare economics uses Sen's (1970) model of social welfare functionals (SWFL), where the information made explicit about states is restrained in two ways: it is information only about individual welfare, and this individual welfare is seen as a single real number. Other information that is implicit in the description of states may still affect social rankings, but such effects are hard to study formally in the model.

Some departures from this model have been presented. This includes multidimensional aggregation models, whose explicit information about each person is a vector of real numbers: in Roberts (1995) this vector contains different opinions on the person's welfare (Sam's opinion, Mary's opinion, ...), and in List (2004) the vector contains different welfare types (the person's opulence, life expectancy, ...). While the latter two models make welfare-information more detailed, Blackorby, Bossert, and Donaldson (2005) make a person's nonwelfare-characteristics explicit, but eliminate their effects by imposing conditions on aggregation.

Unlike these departures, I will place no restriction on the sort of explicit information. Specifically, I consider an arbitrary set $K$ of issues, where $2 \leq$ $|K|<\infty$. An issue could be anything about a state deemed relevant for its evaluation: it may but need not relate to a person, and if it does it may but need not relate to welfare. As many examples of issues will involve individuals, let $N$ be the set of persons of society, where $2 \leq|N|<\infty$.

A performance function for an issue $k \in K$ is a function $U_{k}: X \rightarrow \mathbf{R}$, which measures how well each state performs on the issue $k$. For instance, an issue $k \in K$ could be:

- Peter's pleasure, so that $U_{k}(x)$ quantifies Peter's pleasure in $x$;

- the moral acceptability of Peter's pleasure, so that $U_{k}(x)$ is low if in $x$ Peter derives his pleasure from torturing someone;

- Jane's goodness judgment of the social state, so that $U_{k}(x)$ is high if Jane finds society $x$ good;

- Peter's freedom, so that $U_{k}(x)$ measures how free Peter is in $x$;

- social stability, so that $U_{k}(x)$ is low if there is a civil war in $x$;

- a value like freedom of speech or the preservation of nature, so that $U_{k}(x)$ 
measures the degree to which the value is respected in state $x$.

For later reference, I give some precise examples of sets of issues $K$.

(i) Standard welfare economics considers for each person $i \in N$ the issue " $i$ 's welfare". We can define $K=N$ by identifying issues with individuals.

(ii) In Roberts (1995), we can put $K=\{(i, d): i \in N, d \in D\}$, where $D$ is a set of persons with opinions on welfare and $(i, d)$ is the issue " $i$ 's welfare in $d$ 's opinion".

(iii) In List (2004), $K$ can be defined as in (ii), where $D$ is a now set welfare types (income, health,...$)$ and $(i, d)$ is the issue " $i$ 's welfare of type $d "{ }^{1}{ }^{1}$

(iv) A case of non-person-specific issues is $K=\{\mathrm{S}, \mathrm{H}, \mathrm{E}\}$, with the three issues "social stability", "health". "equality".

(v) $K$ might contain (among other issues) for each person $i \in N$ the issues Welf $_{i}$ (" $i$ 's welfare"), Pref $_{i}$ (" $i$ 's preference") and $\operatorname{Judg}_{i}$ (" $i$ 's judgment"), as discussed in Section 3.

(vi) Addressing one of Sen's concerns, $K$ might contain (among other issues) for each $i \in N$ the issue $\mathrm{SoW}_{i}$ of (the moral acceptability of) the $i$ 's source of welfare.

A profile is a family of performance functions $U=\left(U_{k}\right)_{k \in K}-$ one performance function for each issue. It can be seen as a single function $U: X \rightarrow \mathbf{R}^{K}{ }^{2}{ }^{2}$ An evaluation functional is a function $F$ that assigns to each profile $U$ from some domain $\mathcal{D}$ of ("admissible") profiles a (social) betterness ordering $\succeq_{U}=F(U)$, i.e. a reflexive, transitive and complete binary relation on $X,{ }^{3}$ with strict and indifference components denoted $\succ_{U}$ and $\sim_{U}$, respectively. ${ }^{4} F$ reflects how the evaluation of states depends on their performance on the issues in $K$.

Despite of the interpretational difference, a formal analogy between this aggregation problem and the standard one can be obtained by identifying issues with individuals and performance functions with individual welfare functions. So the rich collection of welfare economical results can be re-interpreted as results on the present aggregation problem.

The issues in $K$ can often be naturally classified into sets of issues of similar type, so-called "aspects". Formally, an aspect is simply a non-empty set of issues $A \subseteq K$. Aspects and questions of inter-aspect comparability will play an important role below. Examples of aspects are: in (i) the set $A \subseteq N$ of homeless persons, in (ii) $A=\{(i, d): d \in D\}$ (opinions on $i$ 's welfare), in (iii) $A=\{(i, d): i \in N\}$ (welfare of type $d$ ), in (iv) $A=\{\mathrm{H}\}$ (the single-issue aspect of health), in (v) $A=\left\{\right.$ Welf $\left._{i}: i \in N\right\}$ (welfare), and in (vi) $A=\left\{\mathrm{SoW}_{i}: i \in N\right\}$ (source of welfare).

\footnotetext{
${ }^{1}$ In (ii) and (iii), $D$ is the set of dimensions of the respective multidimensional model.

${ }^{2}$ The Euclidean space $\mathbf{R}^{K}$ is the set of families of real numbers $\left(u_{k}\right)_{k \in K}$ (that is, formally, of functions $f: K \rightarrow \mathbf{R}$ ).

${ }^{3}$ Reflexivity: for all $x \in X, x \succeq_{U} x$; transitivity: for all $x, y, z \in X, x \succeq_{U} y \& y \succeq_{U} z \Rightarrow$ $x \succeq_{U} z$; completeness: for all distinct $x, y \in X, x \succeq_{U} y$ or $y \succeq_{U} x$. The completeness requirement, though standard, might in fact be questionable.

${ }^{4}$ For all $x, y \in X, x \succ_{U} y: \Leftrightarrow\left[x \succeq_{U} y\right.$ and not $\left.y \succeq_{U} x\right]$, and $x \sim_{U} y: \Leftrightarrow\left[x \succeq_{U} y\right.$ and $\left.y \succeq_{U} x\right]$.
} 
Any profile $U=\left(U_{k}\right)_{k \in K}$ induces for each aspect $A \subseteq K$ a subprofile, denoted by $U_{A}:=\left(U_{k}\right)_{k \in A}$ and interpretable as a function $U_{A}: X \rightarrow \mathbf{R}^{A}$.

Finally, I use the standard notation $>>, \geq,<<, \leq$ for vector inequalities. ${ }^{5}$

\section{Welfare information, preference information, judgment information}

Henceforth, much of the discussion (but not the formal results) will fucus on the case (v) above, in which $K$ contains (at least) for each person $i \in N$ the issues

- Welf ${ }_{i}$, representing $i$ 's welfare (in the state),

- Pref $_{i}$, representing $i$ 's preference (for the state), and

- $\mathrm{Judg}_{i}$, representing $i$ 's judgment (of the state's goodness).

I now briefly discuss the interpretation of these issues, whose performance functions $U_{\text {Welf }_{i}}, U_{\mathrm{Pref}_{i}}$ and $U_{\mathrm{Judg}_{i}}$ I call $i$ 's welfare function, $i$ 's preference function, and $i$ 's judgment function, respectively. Let $x \in X$ be any state.

Welfare information. $U_{\text {Welf }_{i}}(x)$ represents (the amount of) $i$ 's welfare (or interest) in state $x$, as given by some account of welfare. Depending on the account, $U_{\text {Welf }_{i}}(x)$ might, for instance, be a measure of $i$ 's happiness or experienced pleasure in $x$ (as in traditional utilitarianism), or simply a measure of $i$ 's opulence in $x$, or a measure of the fulfilment of $i$ 's basic needs (for nutrition, health, education, ...), or a Rawlsian index of $i$ 's primary goods in $x$. Under a somewhat different, freedom-type notion of a person's interests/welfare, $U_{\text {Welf }_{i}}$ measures $i$ 's opportunities of some kind; e.g. $U_{\mathrm{Welf}_{i}}$ could be some index of $i$ 's capabilities in $x$. Under yet another account, which avoids any "external" welfare standard, $U_{\text {Welf }_{i}}(x)$ is $i$ 's subjective assessment of her own well-being in $x$. For discussions of different welfare accounts, see for instance Griffin (1986), Mongin and d'Aspremont (1998), Roemer (1996), Sen (1985) and Summer (1996).

Preference information. $U_{\operatorname{Pref}_{i}}(x)$ represents (the amount of) $i$ 's preference for $x$, i.e. the amount to which $i$ "desires" or "wants" $x$. For instance, a rich but altruistic person $i$ might prefer a society $x$ with redistribution to a society $y$ without redistribution ( $\operatorname{so~}_{\operatorname{Pref}_{i}}(x)>U_{\operatorname{Pref}_{i}}(y)$ ), although $i$ 's welfare is higher without redistribution (so $\left.U_{\mathrm{Welf}_{i}}(x)<U_{\mathrm{Welf}_{i}}(y)\right)$. Of our three notions - welfare, preference and judgment - preference is the one closely related to (hypothetical) choice behaviour: if person $i$ prefers state $x$ to state $y$ (i.e. $\left.U_{\operatorname{Pref}_{i}}(x)>U_{\operatorname{Pref}_{i}}(y)\right)$, then she would choose $x$ over $y$ if offered this choice. ${ }^{6}$

\footnotetext{
${ }^{5}$ For any vectors $u, v$, say in $\mathbf{R}^{A}, u>>v: \Leftrightarrow u_{k}>v_{k} \forall k \in A, u \geq v: \Leftrightarrow u_{k} \geq v_{k} \forall k \in A$, $u<<v: \Leftrightarrow u_{k}<v_{k} \forall k \in A$, and $u \leq v: \Leftrightarrow u_{k} \leq v_{k} \forall k \in A$.

${ }^{6}$ But I would not like to follow the revealed preferences school in considering the choice behaviour as providing the meaning of preferences: preferences explain choice, not vice versa.
} 
Under a quite particular account of welfare, the distinction between welfare information and preference information vanishes by definition, i.e. $U_{\mathrm{Welf}_{i}}=$ $U_{\text {Pref }_{i}}$. This account identifies a person's welfare with the fulfilment of her (actual) preference. ${ }^{7}$ While an identification of welfare with preference is often implicitly performed in economics (sadly, I think), it is also frequently criticised, for instance on the grounds of defining away the possibility of non-self-interested preferences (which go against personal welfare); a seminal paper is Sen (1977b). ${ }^{8}$

Note that each of the welfare accounts listed earlier (happiness, primary goods, ...) draws a clear distinction between welfare and preference, and hence between the functions $U_{\text {Welf }_{i}}$ and $U_{\mathrm{Pref}_{i}}$. Also, current welfarism often distinguishes welfare from preference. For instance, Blackorby and Bossert (2004) write: "Individuals [...] may have self-regarding preferences that accord with their well-being [i.e. welfare], but we do not assume that they do. If they do, the individual [welfare] functions are representations of their preferences." Similarly, Blackorby, Bossert and Donaldson (2005) explain that "expressed preference may not always be consistent with individual well-being [i.e. welfare]", because (among other things) preference need not follow personal interest while welfare does so by definition.

Judgment information. ${ }^{9} \quad U_{\operatorname{Judg}_{i}}(x)$ represents the (amount of) social goodness of state $x$ in $i$ 's judgment. Different persons may indeed form different goodness judgments.

Much could (and partly will) be said about the status of judgment information and its (ir)relevance for social betterness. Let me anticipate that, under certain interpretations of aggregation, it would be a category mistake to allow people's goodness judgments to affect social goodness, because personal judgments are evidence for, not determinants of, social goodness. In other aggregation tasks, evidence for goodness is precisely the relevant type of information, which may make judgment information particularly relevant. A more systematic analysis is attempted in Section 8.

Person $i$ 's judgment function $U_{\mathrm{Judg}_{i}}$ could be regarded as the result of $i$ 's personal process of aggregating her own information into her goodness judgments. This aggregation is "personal" in two respects. First, the informational input is what $i$ has access to and considers relevant - for instance welfare information

\footnotetext{
${ }^{7}$ This desire-fulfilment account is popular in modern utilitarianism. But in its pure form it is generally rejected, and replaced by different modified accounts: accounts in which the fulfilment of only certain desires count as part of welfare (e.g. only informed desires, or only morally acceptable desires, or only desires whose fulfilment is experienced by the person, or only desires that are part of the person's aims). These modified desire-fulfilment accounts of welfare let the difference between $U_{\text {Welf }_{i}}$ and $U_{\text {Pref }_{i}}$ re-emerge.

${ }^{8}$ As one consequence, Sen's distinction between sympathy and commitment would become meaningless, because Sen's "commitment" is an other-regarding preference without effect on personal welfare.

${ }^{9} \mathrm{~A}$ very different notion of "judgment information" are judgments expressed in formal logic; such logical judgments form the informational basis in the field of judgment aggregation (e.g. List and Pettit 2002, Dietrich 2004).
} 
if $i$ is a welfarist. Second, the functional dependence of $i$ 's goodness judgments on that information reflects $i$ 's views - for instance, sum-maximisation is used if $i$ is a utilitarian..

Questions of measurability of and comparability between these three information types are discussed in Section 9.

\section{Are multiple issues per individual needed?}

Before proceeding, let me briefly discuss an objection. Suppose $K$ contains only person-specific issues, e.g. $K=\left\{\right.$ Welf $\left._{i}, \mathrm{SoW}_{i}: i \in N\right\}$ or $K=\left\{\right.$ Welf $_{i}$, Pref $_{i}, \mathrm{Judg}_{i}$ : $i \in N\}$. Could we then not have condensed all information relating to the same individual (e.g. her welfare and her source of welfare) into a single index, and take these individual indices as starting points for aggregation? If $K=$ $\left\{\right.$ Welf $\left._{i} ; \operatorname{SoW}_{i}: i \in N\right\}$, this amounts to forming indices $V_{i}:=g\left(U_{\mathrm{Welf}_{i}}, U_{\mathrm{SoW}_{i}}\right)$, $i \in N$, and aggregating $\left(V_{i}\right)_{i \in N}$ instead of $\left(U_{i}\right)_{i \in K}$, which would bring us back to the standard approach.

First, note that it is a strong mathematical restriction to demand that social rankings depend on the profile $\left(U_{i}\right)_{i \in K}$ only through individual indices, in a similar way as it is a very special case that a function from $\mathbf{R}^{100}$ to $\mathbf{R}$ turns out to be a function of an index of the first fifty and an index of the last fifty arguments (granting that indices must satisfy mild regularity properties such as continuity and non-decreasingness in each argument).

Nevertheless, imposing this mathematically special case would become justifiable if a compelling normative argument exists. It appears to me that such an argument would have to establish that what matters about a given individual $i \in N$ is really only a single feature, perhaps $i$ 's "well-being", where this feature happens to depend on various issues (in $K$ ). In the example above, $i$ 's welfare and $i$ 's source of welfare would have no intrinsic value but only instrumental value by contributing to some other, uniquely relevant, feature of $i$, perhaps $i$ 's "well-being". Then could indeed justify taking indices $V_{i}:=g\left(U_{\mathrm{Welf}_{i}}, U_{\mathrm{SoW}_{i}}\right)$, $i \in N$, as the basis of aggregation.

But what would be this uniquely relevant individual feature to which many (possibly quite different) individual features contribute? It can be argued that concepts such as well-being, welfare and pleasure are inherently multidimensional (e.g. Griffin 1986; Sen 1987 uses the term "constitutive plurality"). If this is true, it appears unclear why multiple individual features should matter only through some individual index. The single-index approach would then only have the pragmatic justification of a simplification. In fact, also the two-issue case $K=\left\{\operatorname{Welf}_{i}\right.$; $\left.\mathrm{SoW}_{i}: i \in N\right\}$ would most likely be a simplification, as $U_{\text {Welf }_{i}}$ and $U_{\mathrm{SoW}_{i}}$ are probably themselves indices. 


\section{Welfarism, preferencism, judgmentism}

The position that two states should be ranked solely on the basis of the welfare information about these states is usually called "welfarism". I call "preferencism" and "judgmentism" the analogous positions with welfare information replaced by preference information respectively judgment information. More precisely, consider for any aspect $A \subseteq K$ the following " $A$-ism" condition, referred to as

- welfarism if $A$ is the welfare aspect $A_{\mathrm{Welf}}:=\left\{\right.$ Welf $\left._{i}: i \in N\right\}$,

- preferencism if $A$ is the preference aspect $A_{\text {Pref }}:=\left\{\operatorname{Pref}_{i}: i \in N\right\}$,

- judgmentism if $A$ is the judgment aspect $A_{\mathrm{Judg}}:=\left\{\operatorname{Judg}_{i}: i \in N\right\}$.

Independence of non- $A$ characteristics (" $A$-ism"). For any profiles $U, U^{*} \in \mathcal{D}$ and any states $x, x^{*}, y, y^{*} \in X$, if $U_{A}(x)=U_{A}^{*}\left(x^{*}\right)$ and $U_{A}(y)=$ $U_{A}^{*}\left(y^{*}\right)$ then $x \succeq_{U} y \Leftrightarrow x^{*} \succeq_{U^{*}} y^{*}$.

Informally, $A$-ism requires that the ranking of two states be fully determined by the $A$-information about the two states. Two obvious examples of $A$-ist evaluation functionals are given by

$$
\begin{aligned}
& x \succeq_{U} y \Leftrightarrow \sum_{k \in A} U_{k}(x) \geq \sum_{k \in A} U_{k}(y), \text { for all } x, y \in X \text { and } U \in \mathcal{D} ; \\
& x \succeq_{U} y \Leftrightarrow \min _{k \in A} U_{k}(x) \geq \min _{k \in A} U_{k}(y), \text { for all } x, y \in X \text { and } U \in \mathcal{D} .
\end{aligned}
$$

For instance, taking $A=A_{\text {Welf }}$ in (1) yields standard utilitarianism, and taking $A=A_{\text {Pref }}$ in (2) yields the preferencist rule that maximises the minimal "wantedness" of states across society.

Important examples of preferencist aggregation can be obtained in economic allocation problems, by letting $X$ be the set of possible re-allocations of some fixed initial endowment of goods across a group, and letting the re-allocation happen through some trade mechanism under idealised market conditions. This does not quite define an evaluation functional $F$, because the outcome is not a ranking of all allocations in $X$ but a set of best allocations (equilibrium allocations of some sort). But, abstracting from this difference, the outcome is preferencist: it depends on people's preferences only, since these are which determine people's decisions to sell or buy. In particular, welfare or judgment information has no effect on the allocation (except from indirect, hardly predictable, effects through affecting individual preferences). In fact, not only is the allocation preferencist, but it actually uses only ordinal preference information, i.e. only the preference orderings induced by the functions $U_{\operatorname{Pref}_{i}}, i \in N$. See for instance Roemer (1996) for discussion.

In search of an appealing $A$-ism, each of welfarism, preferencism and judgmentism may appear plausible candidates. Indeed, why not determine the goodness of states from how well-off people are (welfarism)? Or from what people want (preferencism)? Or from what people find socially good (judgmentism)? 
Clearly, the plausibility of each of these positions is damaged by their mutual incompatibility: someone may be well-off in a state without wanting it, or want a state without judging it as socially good, etc.

In general, the larger the set $A$ is, the less problematic $A$-ism becomes (and the weaker this condition becomes logically). For instance, two frequent

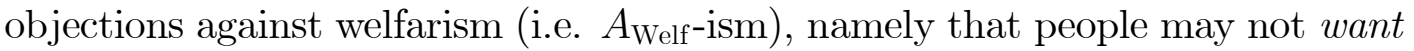
certain welfare respectively that welfare may come from repulsive sources, could not be made against $A_{\text {Welf }} \cup A_{\text {Pref }}$-ism respectively $A_{\text {Welf }} \cup A_{\text {SoW-ism, because }}$ these more comprehensive $A$-isms take into account the neglected information.

A normative defense of any $A$-ism, e.g. of welfarism, preferencism or judgmentism, could be attempted by deriving $A$-ism from arguably more fundamental conditions, in pretty much the same way as welfarism is standardly derived from the conditions of universal domain, independence of irrelevant alternatives, and Pareto indifference - the famous welfarism theorem, proven in different versions, among others by d'Aspremont and Gevers 1977, Sen 1977c, and Blackorby, Bossert and Donaldson 2005. I now present a theorem, whose part (a) is an " $A$-ism theorem" analogous to the welfarism theorem, and whose part (b) deduces an $A$-unanimity principle analogous to the weak Pareto principle from a very plausible global unanimity condition.

In part (a) of the theorem, $A$-ism is derived from the following conditions.

Universal domain. $\mathcal{D}$ is the set of all profiles $U: \mathbf{R}^{K} \rightarrow \mathbf{R}$.

$A$-Indifference respectance. For all profiles $U \in \mathcal{D}$ and all states $x, y \in$ $X$, if $U_{A}(x)=U_{A}(y)$ then $x \sim_{U} y$.

Independence of irrelevant alternatives. For all states $x, y \in X$ and all profiles $U, U^{*} \in \mathcal{D}$, if $U(x)=U^{*}(x)$ and $U(y)=U^{*}(y)$ then $x \succeq_{U} y \Leftrightarrow x \succeq_{U^{*}} y$.

Under universal domain, a social betterness order is generated for any profile of performance functions. Under $A$-indifference respectance, which for $A=A_{\text {Welf }}$ yields standard Pareto indifference, two states are socially indifferent whenever they perform equally well on each issue in $A$. Here, "performing equally well on each issue in $A^{\prime \prime}$ means

- making people equally well-off if $A=A_{\text {Welf }}$,

- being equally wanted if $A=A_{\text {Pref }}$,

- being considered equally good if $A=A_{\text {Judg }}$.

The condition of independence of irrelevant alternatives subtly differs from the standard condition with this name. The standard IIA condition requires that the only welfare information used to rank two states be that about these two states. Our condition requires that the only information about issues in $K$ (not just about issues in $A_{\text {Welf }}$ ) used to rank two states be that about these two states.

Part (b) of our theorem will use the following conditions. 
Global unanimity respectance. For any profile $U \in \mathcal{D}$ and any states $x, y \in X$, if $U(x)>>U(y)$ then $x \succ_{U} y$.

$A$-unanimity respectance. For any profile $U \in \mathcal{D}$ and any states $x, y \in X$, if $U_{A}(x)>>U_{A}(y)$ then $x \succ_{U} y$.

$A$-unanimity respectance states that a state is better than another if it performs better on each issue in $A$, regardless of other issues. If $A=K$ this yields global unanimity respectance. I call the $A$-unanimity respectance

- welfare-unanimity respectance or weak Pareto principle if $A=A_{\mathrm{Welf}}$,

- preference-unanimity respectance if $A=A_{\mathrm{Pref}}$,

- judgment-unanimity respectance if $A=A_{\mathrm{Judg}}$.

These three conditions require, respectively, that a state be ranked above another if it Pareto-dominates the other, or is unanimously preferred to the other, or is unanimously judged better than the other.

While $A$-unanimity respectance may appear problematic for many aspects $A$ (see Sen's (1979) critique of the weak Pareto principle), global unanimity respectance is much less problematic provided that the set of issues $K$ is sufficiently comprehensive. For instance, the frequent argument against the weak Paretianism (i.e. $A_{\text {Welf-unanimity }}$ respectance), namely its ignoring of the source of welfare, does not work against global unanimity respectance if $K$ contains the issues $\mathrm{SoW}_{i}, i \in N$. This is why the additional assumption in part (b) of the following theorem is mild.

Theorem 1 Consider any aspect $A \subseteq K$.

(a) If $F$ satisfies universal domain, independence of irrelevant alternatives, and $A$-indifference respectance, $F$ satisfies $A$-ism.

(b) If also global unanimity respectance holds, A-unanimity respectance holds.

Is part (a) a suitable normative defense of $A$-ism, and is part (b) one of $A$-unanimity respectance? Of course, this will depend on the issues contained in $A$. A welfarist would probably accept the argument if $A=A_{\text {Welf }}$. Someone who objects to welfarism on the grounds that it neglects the source of people's welfare might accept the argument if $A=A_{\text {Welf }} \cup A_{\text {SoW }}$.

For many aspects $A \subseteq K, A$-indifference respectance might be the most controversial premise in Theorem 1 . Indeed, the same reason that may lead one to doubt $A$-ism in the first place (namely the insensitivity to non- $A$ information) may also lead one to doubt $A$-indifference respectance.

The proof of part (a) is more involved than that of the standard welfarism theorem. Instead of presenting a free-standing proof, I will reduce part (a), by some rather counter-intuitive identifications, to Theorem 2 in Blackorby, Bossert and Donaldson (2005).

Proof. (a) Suppose $F$ is as specified. To reduce this claim to Blackorby, Bossert and Donaldson's (2005) Theorem 2, I identify their set $N$ (of individuals) with $A$, their set $\mathcal{S}_{0}$ (of social non-welfare characteristics) with $\mathbf{R}^{K \backslash A}$, and 
each of their sets $\mathcal{S}_{1}, \ldots, \mathcal{S}_{n}$ (of individual non-welfare characteristics) with the singleton $\{0\}$. Then a profile in their sense can be identified with a triple of functions $\Upsilon=\left(\Gamma^{1}, \Gamma^{2}, \Gamma^{3}\right)$, where $\Gamma^{1}$ is a function $X \rightarrow \mathbf{R}^{A}, \Gamma^{2}$ is a function $X \rightarrow \mathbf{R}^{K \backslash A}$, and $\Gamma^{3}$ is a function $X \rightarrow\{0\}^{A}$. Since there is only one function $\Gamma^{3}: X \rightarrow\{0\}^{A}$ (as $\{0\}^{A}$ is a singleton), a profile $\Upsilon=\left(\Gamma^{1}, \Gamma^{2}, \Gamma^{3}\right)$ can be further identified with the pair $\left(\Gamma^{1}, \Gamma^{2}\right)$, which can in turn be identified with a profile a profile in our sense $U: X \rightarrow \mathbf{R}^{K}$ by defining

$$
U_{k}(x):=\left\{\begin{array}{ll}
\Gamma_{k}^{1}(x) & \text { if } k \in A \\
\Gamma_{k}^{2}(x) & \text { if } k \in K \backslash A,
\end{array} \text { for all } x \in X .\right.
$$

Under these identifications, our evaluation functionals are identical to theirs, our conditions of universal domain and independence of irrelevant alternatives are equivalent to their equally named conditions, and our $A$-indifference respectance is equivalent to their Pareto indifference principle. So, by their Theorem $2, F$ is strongly neutral, a condition equivalent to our $A$-ism.

(b) Assume that global unanimity respectance also holds. To show $A$ unanimity respectance, consider any profile $U \in \mathcal{D}$ and any states $x, y \in X$ with $U_{A}(x)>U_{A}(y)$. By universal domain, there is a profile $U^{*} \in \mathcal{D}$ such that $U_{A}(x)=U_{A}^{*}(x), U_{A}(y)=U_{A}^{*}(y)$, and $U_{K \backslash A}^{*}(x)>>U_{K \backslash A}^{*}(y)$. Then $U^{*}(x)>>U^{*}(y)$, and so $x \succ_{U^{*}} y$ by global unanimity respectance. Hence

$(*) x \succeq_{U^{*}} y$ and not $y \succeq_{U^{*}} x$

Further, applying $A$-ism (for $x=x^{*}$ and $y=y^{*}$ ), $x \succeq_{U} y \Leftrightarrow x \succeq_{U^{*}} y$, and so, by $\left(^{*}\right), x \succeq_{U} y$. Applying $A$-ism a second time (now for $x=x^{*}$ and $y=y^{*}$ ), we have $y \succeq_{U} x \Leftrightarrow y \succeq_{U^{*}} x$, and so, again by $(*)$, not $y \succeq_{U} x$. Since $x \succeq_{U} y$ but not $y \succeq_{U} x$, we have $y \succ_{U} x$, as desired.

A final remark. Any $A$-ism $\left(A_{\text {Welf }}\right.$-ism, $A_{\text {Welf }} \cup A_{\text {Pref }}$-ism, ... $)$ is equivalent to the existence of a binary relation $R$ on $\mathbf{R}^{A}$ such that

$$
x \succeq_{U} y \Leftrightarrow U_{A}(x) R U_{A}(y) \text { for all } x, y \in X \text { and all } U \in \mathcal{D} .
$$

For instance, in the case of judgmentism $\left(A=A_{\mathrm{Judg}}\right), x \succeq_{U} y \Leftrightarrow U_{\mathrm{Judg}}(x) R U_{\mathrm{Judg}}(y)$. By (3), the task of ranking social states reduces to the task of ranking $A$ dimensional vectors. In this sense, $F$ is represented by $R$.

If $F$ has universal domain, $R$ is unique and it is an ordering (i.e. is reflexive, transitive and complete). In the case of welfarism $\left(A=A_{\text {Welf }}\right), R$ may be called a social welfare ordering, following Gevers (1979). In the case of preferencism $\left(A=A_{\text {Pref }}\right)$ or judgmentism $\left(A=A_{\text {Judg }}\right)$, one might call $R$ a social preference ordering or a social judgment ordering, respectively.

If $R$ is moreover continuous ${ }^{10}$, then by Debreu's representation theorem $R$ is representable by a continuous function $f: \mathbf{R}^{A} \rightarrow \mathbf{R}$ in the sense that, for any $u, v \in \mathbf{R}^{A}, u R v \Leftrightarrow f(u) \geq f(v)$. ( $f$ may be called a Bergson-Samuelson social

\footnotetext{
${ }^{10}$ that is, for each $u \in \mathbf{R}^{A}$ the sets $\left\{v \in \mathbf{R}^{A}: v R u\right\}$ and $\left\{v \in \mathbf{R}^{A}: u R v\right\}$ are topologically closed in $\mathbf{R}^{A}$
} 
welfare function if $A=A_{\text {Welf }}$ ). For instance, in our examples (1) and (2) we have

$$
f(u)=\sum_{k \in A} u_{k} \text { respectively } f(u)=\min _{k \in A} u_{k}, \text { for all } u \in \mathbf{R}^{A} .
$$

$F$ is represented by $f$ in the sense that social betterness maximises $f \circ U_{A}$, i.e.

$$
x \succeq_{U} y \Leftrightarrow f\left(U_{A}(x)\right) \geq f\left(U_{A}(y)\right) \text { for all } x, y \in X \text { and all } U \in \mathcal{D} .
$$

For instance, social betterness maximises $f \circ U_{\text {Welf }}$ in the case of welfarism, $f \circ U_{\text {Pref }}$ in the case of preferencism, and $f \circ U_{\text {Judg }}$ in the case of judgmentism.

\section{A problem of preferencism: its favouring of the selfish}

I should record a potentially serious objection to preferencism (and the associated weak Pareto principle). As is sometimes noted (e.g. Roemer 1995, ch. 1.4), if some individuals $i$ have self-regarding preferences (that reflect their own welfare, perhaps to the extent that $U_{\text {Pref }_{i}}=U_{\text {Welf }_{i}}$ ), and the other individuals $i$ have other-regarding preferences (that incorporate the welfare of others, perhaps to the extent that $U_{\mathrm{Pref}_{i}}$ is a function of of the functions $\left.U_{\text {Welf }_{j}}, j \in N \backslash\{i\}\right)$, then respecting only people's preferences implies respecting more the welfare of some ("selfish") people than the welfare of other ("altruistic") people. For instance, if state $y \in X$ arises from state $x \in X$ by a redistribution that makes all "altruistic" people poor and all "selfish" people rich, then preferencist rules (such as the maximisation of sum-total preference $\sum_{i \in N} U_{\operatorname{Pref}_{i}}$ ) may well rank $y$ over $x$, which appears unfair. Preferencism might appear even more problematic when some persons' preferences not only ignore the welfare of others, but are directed against the welfare of others (wanting others to suffer) or against their personal welfare (masochism).

This casts doubts on preferencism, and thus also on allocation mechanisms of (idealised) market economies, interpreted as implementations of (choice rules induced by) preferencist evaluation functionals (see Section 5).

\section{A problem of welfarism: its paternalism}

A paternalism charge is often brought against non-welfarist positions. By contrast, I now argue that welfarism is more vulnerable to a paternalism charge than preferencism or judgmentism. When analysing different $A$-isms (e.g. welfarism), I will focus not directly on the $A$-ism condition but on $A$-unanimity respectance, which naturally comes together with $A$-ism by part (b) of Theorem 1.

Consider states $x, y \in X$, and suppose $x$ welfare-dominates $y$, i.e. gives everyone a higher welfare $\left(U_{\text {Welf }}(x)>>U_{\text {Welf }}(y)\right)$. Suppose also that one 
of the two states preference-dominates the other $\left(U_{\text {Pref }}(x)>>U_{\text {Pref }}(y)\right.$ or $U_{\text {Pref }}(y)>>U_{\text {Pref }}(x)$ ), and one of the two states judgment-dominates the other $\left(U_{\text {Judg }}(x)>>U_{\text {Judg }}(y)\right.$ or $\left.U_{\text {Judg }}(y)>>U_{\text {Judg }}(x)\right)$. Such situations can frequently be encountered. ${ }^{11}$ Table 1 contains what might appear to be the non-paternalist social ranking of $x$ and $y$, depending on the direction of the various dominations.

\begin{tabular}{|c|c|c|c|c|}
\hline & $\begin{array}{c}\text { which state } \\
\text { welfare-domin. } \\
\text { the other? }\end{array}$ & $\begin{array}{c}\text { which state } \\
\text { preference-domin. } \\
\text { the other? }\end{array}$ & $\begin{array}{c}\text { which state } \\
\text { judgment-domin. } \\
\text { the other? }\end{array}$ & $\begin{array}{c}\text { non- } \\
\text { paternalist } \\
\text { ranking }\end{array}$ \\
\hline case $1:$ & $x$ & $x$ & $x$ & $x \succ_{U} y$ \\
\hline case $2:$ & $x$ & $y$ & $y$ & $y \succ_{U} x$ \\
\hline case $3:$ & $x$ & $x$ & $y$ & depends \\
\hline case $4:$ & $x$ & $y$ & $x$ & depends \\
\hline
\end{tabular}

Table 1: Which social ranking of $x$ and $y$ is non-paternalist (arguably)?

In case $1, x$ dominates $y$ in all three respects, and so non-paternalism clearly prescribes the ranking $x \succ y$. In case 2, $y$ is higher than $x$ in everyone's preference and judgment, although $y$ gives everyone less welfare. In my view, non-paternalism requires the ranking $y \succ_{U} x$, because it would appear paternalist to give people welfare that they neither want nor judge as good. More generally, one might regard welfarism as paternalist, and $A_{\text {Pref }} \cup A_{\text {Judg-ism }}$ as non-paternalist.

Cases 3 and 4 are more subtle, as people's unanimous preference contradicts their unanimous goodness judgment. Which ranking of $x$ and $y$ is nonpaternalist? Presumably, any answer would depend on the interpretation and role of the social ordering $\succeq_{U}$. If we (re-)interpret $\succeq_{U}$ as representing social preferences rather than (moral) goodness comparisons ${ }^{12}$ then non-paternalism requires these social preferences to follow people's unanimous preferences, not judgments. Indeed, the unanimously wanted must be socially wanted (note: I do not say here "socially good", given the interpretation of $\left.\succeq_{U}\right)$. Judgmentism thus appears paternalist and preferencism non-paternalist. But what if $\succeq_{U}$ represents a (moral) goodness ordering? At first, one might be tempted to take judgmentism as non-paternalist, since overruling people's judgments would mean imposing external judgments on the group. But a closer look at the question reveals that we need further distinctions (explained in Section 8). Possibly, judgmentism could be viewed as non-paternalist in an indicative aggregation task (where the profile $U$ is used as evidence for social goodness), whereas preferencism could be viewed as non-paternalist in a constitutive aggregation task

\footnotetext{
${ }^{11}$ One such scenario could be that citizens have to either cut a forest $(x)$ or leave it $(y)$, where all citizens gain from cutting the forest $\left(U_{\text {Welf }}(x)>>U_{\text {Welf }}(y)\right)$, want the forest to be cut for selfish reasons $\left(U_{\text {Pref }}(x)>>U_{\text {Pref }}(y)\right)$ but judge cutting the forest as morally bad for environmental reasons $\left(U_{\mathrm{Judg}}(y)>>U_{\mathrm{Judg}}(x)\right)$.

${ }^{12}$ Like for an individual, we can think of society as wanting something that is not morally good, and vice versa.
} 
(where the profile $U$ determines/constitutes social goodness).

In summary, welfarism appears to be paternalist, preferencism and judgmentism may or may not be considered as paternalist, and $A_{\text {Pref }} \cup A_{\text {Judg-ism }}$ appears non-paternalist.

Finally, I should note that non-paternalism need not be treated as a holy grail. One may well defend a (paternalist) overruling of certain unanimous preferences or judgments. For instance, if the population unanimously prefers and judges as better a fascist dictatorship as compared to some democracy, then the social betterness of the democracy might still be defended on the grounds of performing better on other issues in $K \backslash\left(A_{\text {Pref }} \cup A_{\text {Judg }}\right)$ such as the informedness or moral integrity of individual preferences or judgments, or the state's constitution or certain values or rights.

\section{When is judgment information (ir)relevant? Two distinct aggregation tasks}

The question which information is (ir)relevant to social betterness, and hence whether $A$-ism is justified for any given aspect $A \subseteq K$, often depends on the aggregation task under consideration. In this section, I distinguish two such aggregation tasks, and assess the (ir)relevance of judgment information under each of them.

Two distinct aggregation tasks. To begin with an analogy, suppose the task is not to answer the question "Under which circumstances is state $x$ better than state $y$ ?" but "Under what circumstances did it snow last night?". If this question is understood as asking "What determines whether it snowed?", the answer is presumably "certain conditions of temperature and humidity last night". If the question is instead understood as asking "What makes us know whether it snowed?", the answer is presumably "snow everywhere today". What is of interest is in the first case the determinants/origins of snowing, and in the second case the evidence for snowing.

Similarly, one should distinguish the following two aggregation tasks. ${ }^{13}$

- Constitutive aggregation. Here, the profile $U$ contains what determines (or: constitutes, makes up, is the reason for or origin of) true social goodness. So, $x \succeq_{U} y$ means " $x$ is at least as good as $y$ because the profile is $U$ ". Note that this aggregation task may be purely theoretical, as the determinants $U$ may be unavailable.

- Indicative aggregation. Here, the profile $U$ contains the informational or evidential clues used to form social betterness judgments or estimates. So $x \succeq_{U} y$ means " $x$ is considered at least as good as $y$ based on the information that the profile is $U^{\prime \prime}$. Note that such goodness estimates are based on possibly insufficient (perhaps even misleading) information $U$, such as rough surrogates

\footnotetext{
${ }^{13}$ It is thanks to Christian List's advice that I use the terms "constitutive" and "indicative".
} 
or indicators. So $\succeq_{U}$ may differ from the "true" social ordering obtained in a constitutive aggregation task.

Examples. Both aggregation tasks are frequently discussed. For instance, classical utilitarianism claims that the only determinants of social betterness are the individual happiness levels; so that, in a constitutive aggregation task, $F$ should be $A$-ist with $A$ the set of individual happiness issues. But, as individual happiness is hardly accessible, the utilitarian may turn in practice to an indicative aggregation task, and use profiles $U$ containing information such as individual judgments on sum-total happiness, or rough indicators of individual happiness.

The welfarist claim that only welfare information can matter refers to the constitutive aggregation task. This welfarist claim is perfectly compatible with allowing judgment information to enter an indicative aggregation task. So judgmentism and welfarism are not in a conflict if judgmentism is restricted to indicative aggregation tasks.

Roberts' (1995) aggregation of different opinions on different individuals' welfare can be interpreted as an indicative aggregation task.

When is judgment information relevant? Clearly, as people's judgments may indicate social goodness, judgment information may be relevant in for indicative aggregation, perhaps even to the point of judgmentism (where only judgment information is used).

Now consider a constitutive aggregation task. Under standard notions of social goodness (for instance welfarist ones), individual goodness judgments are not determinants of social goodness: believing that a state is good does not make the state good. I should however mention that one could, perhaps, reject an independent notion of goodness and argue that "social goodness" has no meaning beyond that of a "summary" of subjective views. In this case, individual goodness judgments do determine/constitute social goodness, and the constitutive aggregation task becomes a judgmentist one.

\section{$9 \quad$ An impossibility result on multi-aspect-based social goodness}

The objections that can be raised against $A$-ist positions for many aspects $A \subseteq K$, such as those discussed above against welfarism and preferencism, suggest to give up any narrow $A$-ist position and instead base social goodness on multiple aspects. One could imagine to combine information on aspects such as welfare, preference, judgments, source of welfare, fulfilment of rights, and so on.

I consider such a multi-aspect approach to be important (at least conceptually), but I have to address an obstacle that it faces related to the non- 
comparability between sufficiently different aspects. Combined with other conditions, an impossibility theorem will emerge. Like for Arrow's theorem, the impossibility can - and should - be overcome, but the escape-route appears narrower, or so I will argue in Section 10.

Formally, our theorem is closely related (but not identical) to results derived in different contexts by Roberts (1995), Khmelnitskaya and Weymark (2000), and List (2004), who all study non-comparabilities between certain sets of information (where each set contains, respectively, a person's opinions on welfare, welfare information about similar individuals, and welfare information of a given type). As a side effect, our theorem will close a gap in List's (2004) proof.

Suppose that we want to combine, for instance, welfare, preference and judgment information, by constructing an $A_{\text {Welf }} \cup A_{\text {Pref }} \cup A_{\text {Judg-ist evaluation }}$ functional. To combine these three aspects attractively, certain comparisons between these aspects should plausibly be allowed (i.e. be built into the evaluation functional $F$ ). But is it meaningful to say, for instance, that person $i$ has more welfare in $x$ than preference for $x$ ? Or that the (moral) goodness gain from $x$ to $y$ in person's $i$ 's judgment exceeds person $j$ 's welfare gain from $x$ to $y$ ? Presumably, negative answers apply both times.

Or, suppose that, addressing Sen's concerns about sources of welfare, we want to combine welfare and source-of-welfare information through an $A_{\text {Welf }} \cup$ $A_{\mathrm{SoW}}$-ist evaluation functional. It appears meaningless to call some welfare higher than the moral acceptability of some source of welfare.

To formalise inter-aspect comparisons, let $\mathcal{A}$ be a partition of the set of issues $K$ into (mutually exclusive and exhaustive) aspects $A \subseteq K$. Interpretationally, any two distinct aspects $A, A^{*} \in \mathcal{A}$ should be of different nature, whereas two issues within the same aspect $A \in \mathcal{A}$ may have similar nature. For instance, if $K=\left\{\right.$ Welf $_{i}$, Pref $\left._{i}, \operatorname{Judg}_{i}: i \in N\right\}$ then, plausibly, $\mathcal{A}=\left\{A_{\text {Welf }}, A_{\text {Pref }}, A_{\text {Judg }}\right\}$; and if $K=\left\{\right.$ Welf $_{i}$, SoW $\left.i: i \in N\right\}$ then, plausibly, $\mathcal{A}=\left\{A_{\text {Welf }}, A_{\text {SoW }}\right\}$. For other concrete examples, consider the situations (i)-(iv) in Section 2.

(i) (standard welfare economics, $K=N$ ) Following Khmelnitskaya (1999) and Khmelnitskaya and Weymark (2000), we may let $\mathcal{A}$ consist of subgroups of "similar" persons.

(ii) (Roberts' 1995 model of opinions on welfare, $K=\{(i, d): i \in N, d \in D\}$ ) We may put $\mathcal{A}=\{\{(i, d): i \in N\}: d \in D\}$, where an aspect $\{(i, d): i \in N\}$ represents the opinions of person $d$.

(iii) (List's 2004 model of multi-dimensional welfare, $K$ as in (ii)) We may define $\mathcal{A}$ as in (ii); an aspect $\{(i, d): i \in N\}$ now represents all welfare information of one type $d$ (e.g. all information on individual life expectancies).

(iv) $(K=\{\mathrm{S}, \mathrm{H}, \mathrm{E}\}$, with issues "social stability" (S), "health" $(\mathrm{H})$, and "equality" (E)) We may put $\mathcal{A}=\{\{\mathrm{S}\},\{\mathrm{H}\},\{\mathrm{E}\}\}$ (each aspect is a singleton).

The exclusion of inter-aspect comparisons has been defended for the cases (i)-(iii) by the respective authors; the exclusion appears similarly (or even more) defensible for the cases (iv), $\mathcal{A}=\left\{A_{\text {Welf }}, A_{\text {Pref }}, A_{\text {Judg }}\right\}$, and $\mathcal{A}=\left\{A_{\text {Welf }}, A_{\text {SoW }}\right\}$, in each of which $\mathcal{A}$ contains aspects of very different nature. 
To exclude inter-aspect comparisons, I use the standard route of imposing invariance conditions. Suppose that an equivalence relation $\equiv$ on the set of profiles $U: X \rightarrow \mathbf{R}^{K}$ is given, representing informational equivalence of profiles. Two profiles $U, U^{*}$ with $U \equiv U^{*}$ contain precisely the same information. It then becomes justified to require that $\succeq_{U}=\succeq_{U^{*}}$ for all $U, U^{*} \in \mathcal{D}$ with $U \equiv U^{*}$, i.e. that the function $F$ is constant on each equivalence class.

We say that $\equiv$ satisfies inter-aspect non-comparability (w.r.t. partition $\mathcal{A}$ ) if $\equiv$ is a product of equivalence relations in an obvious sense: there exists to each aspect $A \in \mathcal{A}$ an equivalence relation $\equiv_{A}$ on the set of $A$-subprofiles $V: X \rightarrow \mathbf{R}^{A}$ (representing informational equivalence of $A$-subprofiles) such that, for all profiles $U, U^{*}: X \rightarrow \mathbf{R}^{K}$,

$$
U \equiv U^{*} \Leftrightarrow\left[U_{A} \equiv_{A} U_{A}^{*} \text { for all aspects } A \in \mathcal{A}\right] .
$$

In words, two profiles are informationally equivalent just in case, for each aspect $A \in \mathcal{A}$, the two $A$-subprofiles are informationally equivalent. Any $\equiv$-equivalence class is then the Cartesian product of the $\equiv_{A}$-equivalence classes, $A \in \mathcal{A}$; that is, $[U]_{\equiv}=\times_{A \in \mathcal{A}}\left[U_{A}\right]_{\equiv_{A}}$ for each profile $U: X \rightarrow \mathbf{R}^{K} \cdot{ }^{14}$

For any aspect $A \in \mathcal{A}$, the equivalence relation $\equiv_{A}$ represents particular assumptions on the measurability of issues in $A$ and their (intra-aspect) comparability. So $\left(\equiv_{A}\right)_{A \in \mathcal{A}}$ is a family of (intra-aspect) informational assumptions, i.e. a family of measurability and comparability assumptions, one for each aspect $A \in \mathcal{A}$. To construct an informational assumption $\equiv$ satisfying interaspect non-comparability, it is sufficient to formulate a family of intra-aspect comparability and measurability assumptions $\left(\equiv_{A}\right)_{A \in \mathcal{A}}$, and to define $\equiv$ as the product of these relations. Some aspects $A \in \mathcal{A}$ (e.g. the preference aspect $\left.A_{\text {Pref }}\right)$ might be ordinally measurable and fully comparable ${ }^{15}$, other aspects (e.g. welfare $A_{\text {Welf }}$ and judgment $A_{\text {Judg }}$ ) might be cardinally measurable and unit-comparable, and even other aspects (e.g. sources of welfare $A_{\mathrm{SoW}}$ ) might be cardinally measurable and fully comparable.

$F$ respects this informational restriction if it obeys the following condition.

Inter-aspect non-comparable $\left(\equiv_{A}\right)_{A \in \mathcal{A}^{-}}$information. For any profiles $U, U^{*} \in \mathcal{D}$, we have $\succeq_{U}=\succeq_{U^{*}}$ if, for each aspect $A \in \mathcal{A}, U_{A} \equiv_{A} U_{A}^{*}$.

Taking the case of standard welfare economics $(K=N)$ with $\mathcal{A}=\{\{i\}: i \in$ $N\}$, the condition becomes one of inter-personal non-comparability, examples of which are: ordinal non-comparability (here each aspect, i.e. personal welfare,

\footnotetext{
${ }^{14}$ If $\equiv$ satisfies inter-aspect non-comparability, the family $\left(\equiv_{A}\right)_{A \in \mathcal{A}}$ whose product $\equiv$ is is unique and can be retrieved from $\equiv$ as follows: for any $A \in \mathcal{A}$ any any $A$-subprofiles $V, V^{*}: X \rightarrow \mathbf{R}^{A}$, define $V \equiv{ }_{A} V^{*}: \Leftrightarrow\left[U \equiv U^{*}\right.$ for some profiles $U, U^{*}: X \rightarrow \mathbf{R}^{K}$ with $\left.U\right|_{A}=V$ and $\left.\left.U^{*}\right|_{A}=V^{*}\right]$.

${ }^{15}$ If $A$ is ordinally measurable fully comparable, then, for any $A$-subprofile $V: X \rightarrow \mathbf{R}^{A}$ and any strictly increasing transformation $\phi: \mathbf{R} \rightarrow \mathbf{R}, V$ is informationally equivalent to the transformed subprofile $\left(\phi \circ V_{k}\right)_{k \in A}$, i.e. $V \equiv_{A}\left(\phi \circ V_{k}\right)_{k \in A}$. So $V \sim_{A}\left(V_{k}+1\right)_{k \in A} \sim_{A}$ $\left(\exp \circ V_{k}\right)_{k \in A} \sim_{A} \ldots$
} 
is ordinally measurable), and cardinal non-comparability (here each aspect, i.e. personal welfare, is cardinally measurable). ${ }^{16}$

In the impossibility result, I assume that each aspect $A \in \mathcal{A}$ is cardinally measurable and fully (intra-aspect) comparable. Given this form of the equivalence relations $\equiv_{A}, A \in \mathcal{A}$, the above condition becomes as follows. A transformation $\phi: \mathbf{R} \rightarrow \mathbf{R}$ is called increasing affine if there are fixed numbers $a \in \mathbf{R}$ and $b>0$ such that $g(x)=a x+b$ for all $x \in \mathbf{R}$. Also, for any profile $U=\left(U_{k}\right)_{k \in K}$ and any family $\phi=\left(\phi_{k}\right)_{k \in K}$ of transformations $\phi_{k}: \mathbf{R} \rightarrow \mathbf{R}, \mathrm{I}$ write $\phi \circ U$ for the ("transformed") profile $\left(\phi_{k} \circ U_{k}\right)_{k \in K}$.

Inter-aspect non-comparable cardinal information (w.r.t. $\mathcal{A}$ ). For any profiles $U, U^{*} \in \mathcal{D}$, we have $\succeq_{U}=\succeq_{U^{*}}$ if $U^{*}=\phi \circ U$ for some family $\phi=$ $\left(\phi_{k}\right)_{k \in K}$ of increasing affine transformations such that $\phi_{k}=\phi_{l}$ for any issues $k, l$ from the same aspect $A \in A$.

This requires the social betterness ordering $\succeq_{U}$ to remain unchanged whenever each performance function in the profile $U$ is subjected to some (possibly aspect-dependent) increasing affine transformation. For instance, if $A_{\text {Judg }} \in \mathcal{A}$, the condition requires the ordering $\succeq_{U}$ to remain unchanged if in $U$ we replace each individual judgment function $U_{\mathrm{Judg}_{i}}$ by the new function $10+5 U_{\mathrm{Judg}_{i}}$.

Further, the result will use the following continuity notion.

Continuity. For every profile $U \in \mathcal{D}$ and every states $x, y \in X$ with $x \succ_{U} y$, we have $x \succeq_{\bar{U}} y$ for at least one profile $\bar{U} \in \mathcal{D}$ such that $\bar{U}(x) \leq U(x)$ and $\bar{U}(y) \geq U(y)$, where at least one of these vector inequalities is strict in each component.

Informally, a social preference $\left(x \succ_{U} y\right)$ shouldn't be reversed for at least one modification of the profile that reduces the performance $x$ and increases that of $y$. The condition is weak because sufficiently small changes of the profile should not reverse strict preferences; note that $\bar{U}$ can indeed be chosen arbitrarily close to $U$. The condition is weaker than other conditions with a perhaps more straightforward continuity interpretation. ${ }^{17}$

Finally, I call an aspect $A \subseteq K$ dictatorial if there exists a function $f$ : $\mathbf{R}^{A} \rightarrow \mathbf{R}$ (an index of the aspect $A$, or $A$-index), increasing with an increase in

\footnotetext{
${ }^{16}$ For an excellent overview of different notions of informational equivalence, see Bossert and Weymark (2004).

${ }^{17} \mathrm{An}$ (at least under universal domain) stronger condition is that, for every profile $U \in \mathcal{D}$ and every states $x, y \in X$ with $x \succ_{U} y$, there is an $\epsilon>0$ such that $x \succeq_{\bar{U}} y$ for all profiles $\bar{U} \in \mathcal{D}$ in the $\epsilon$-environment of $U$ (i.e., $\sup _{z \in X, k \in K}\left|\bar{U}_{k}(z)-U_{k}(z)\right|<\epsilon$ ). If $F$ is representable by an ordering $R$ on $\mathbf{R}^{K}$ (i.e., for any $x, y \in X$ and $U \in \mathcal{D}, x \succeq_{U} y \Leftrightarrow U(x) R U(y)$ ), our condition is weaker than the continuity of $R$, a condition on $F$ that was first used by Maskin (1978) and implies that $R$ is representable by a continuous function $g: \mathbf{R}^{K} \rightarrow \mathbf{R}$ by Debreu's representation theorem.
} 
each argument, ${ }^{18}$ such that

$$
f\left(U_{A}(x)\right)>f\left(U_{A}(y)\right) \Rightarrow x \succ_{U} y, \text { for all } x, y \in X \text { and } U \in \mathcal{D},
$$

if (4) even holds with " $\Leftrightarrow$ " instead of " $\Rightarrow$ ", I call $A$ strongly dictatorial. ${ }^{19}$

A dictatorial aspect is lexically prior in the sense that (issues from) other aspects come into play only when comparing two states that are ranked equally by the $A$-index. If an aspect is even strongly dictatorial, other information is entirely irrelevant: it doesn't even come into play when two states are ranked equally by the $A$-index, since such states will be automatically indifferent.

Theorem 2 Let F satisfy universal domain, independence of irrelevant alternatives, global unanimity respectance, and inter-aspect non-comparable cardinal information (with respect to some partition $\mathcal{A}$ of $K$ into aspects). Then:

(a) Some aspect $A \in \mathcal{A}$ is dictatorial, which implies $A$-unanimity respectance.

(b) If $F$ is also continuous, $A$ is strongly dictatorial, which implies $A$-ism.

As mentioned, Theorem 2 is closely related to previous results, translated into our model of arbitrary issues. It actually implies List's (2004) two central theorems (theorems 2 and 3), for which he did not provide a full proof. ${ }^{20}$

Note also that part (a) implies (Sen's 1970 cardinal strengthening of) Arrow's Theorem by taking $K=N$ and $\mathcal{A}=\{\{i\}: i \in N\}$.

As a self-contained proof would be extensive, I will essentially reduce part (a) to Theorem 2 in Khmelnitskaya and Weymark (2000) via Roberts' (1980) weak welfarism theorem in Hammond's (1996) corrected version.

Proof. Let $F$ satisfy the specified conditions. By identifying issues with individuals, these conditions become equivalent to the analogous standard conditions. Notationally, the restriction of a vector $u \in \mathbf{R}^{K}$ to an aspect $A \subseteq K$ is denoted $u_{A}$ (i.e. $\left.u_{A}:=\left(u_{k}\right)_{k \in A}\right)$.

Further, for any profile $U: X \rightarrow \mathbf{R}^{K}$, the binary relation $\succ_{U}$ on $X$ (of strong strict preference) is defined as follows (see Roberts 1980): for any states $x, y \in X, x \succ y$ holds if and only if $x \succ_{\bar{U}} y$ for some profile $\bar{U} \in \mathcal{D}$ with

$$
\bar{U}(x)<<U(x), \bar{U}(y)>>U(y) \text {, and } \bar{U}(z)=U(z) \forall z \in X \backslash\{x, y\} .
$$

(We say strong strict preference since $x$ is preferred to $y$ even after reducing each issue's performance on $x$ and raising each issue's performance on $y$.)

\footnotetext{
${ }^{18}$ i.e., for every $u, v \in \mathbf{R}^{A}$, if $u>>v$ then $f(u)>f(v)$

${ }^{19}$ In case $K=N$, an individual $i \in N$ is (strongly) dictatorial in the standard sense of welfare economics if and only if the singleton aspect $\{i\}$ is (strongly) dictatorial in our sense.

${ }^{20}$ List reduces his results to a (correct) theorem that he attributes to Roberts (1995); in fact, Roberts only proves a related theorem (with stronger notions of Pareto and dictatorship). To derive List's results from Theorem 2, note that his dominating welfare dimensions (and dictatorial individuals) are examples of dictatorial aspects (where List uses the term "strictly increasing" for "increasing with an increase in each argument").
} 
(a) The proof of this part proceeds in four steps.

1. I first show that strong strict preference is invariant under the same transformations as the social ordering $\succeq_{U}$ :

$\left(^{*}\right)$ For any profiles $U, U^{*}: X \rightarrow \mathbf{R}^{K}$, we have $\succ \succ_{U}=\succ \succ_{U^{*}}$ if $U^{*}=\phi \circ U$ for some family $\phi=\left(\phi_{k}\right)_{k \in K}$ of increasing affine transformations such that $\phi_{k}=\phi_{l}$ for any issues $k, l$ from the same aspect $A \in A$.

Let $U, U^{*}, \phi$ be as specified. Consider any states $x, y \in X$. I only show that $x \succ \succ_{U} y \Rightarrow x \succ \succ_{U^{*}} y$, as the converse implication holds analogously. So assume $y \succ_{U} y$. Hence $x \succ_{\bar{U}} y$ for some profile $\bar{U} \in \mathcal{D}$ such that

$$
\bar{U}(x)<<U(x), \bar{U}(y)>>U(y) \text {, and } \bar{U}(z)=U(z) \forall z \in X \backslash\{x, y\} .
$$

I define the profiles $\bar{U}^{*}: X \rightarrow \mathbf{R}^{K}$ as the cardinal transformations of $U^{*}$, i.e. $\bar{U}^{*}:=\phi \circ \bar{U}$. By universal domain, $\bar{U}^{*} \in \mathcal{D}$, and so $\succeq_{\bar{U}}=\succeq_{\bar{U}^{*}}$ by the assumption of inter-aspect non-comparable cardinal information. So $\succ_{\bar{U}}=\succ_{\bar{U}^{*}}$. Hence, as $x \succ_{\bar{U}} y$, we have $x \succ_{\bar{U}^{*}} y$. Further, since any (in)equality is preserved if each side is subjected to the same strictly increasing transformation, (5) implies that

$$
\bar{U}^{*}(x)<<U^{*}(x), \bar{U}^{*}(y)>>U^{*}(y) \text {, and } \bar{U}^{*}(z)=U^{*}(z) \forall z \in X \backslash\{x, y\} .
$$

This together with $x \succ_{\bar{U}^{*}} y$ entails that $x \succ_{U^{*}} y$, as desired.

2. To apply Roberts' (1980) weak welfarism theorem in Hammond's (1996) corrected form, we first need to check that Hammond's pairwise continuity condition holds, i.e. that

(PC) for each $\epsilon \in \mathbf{R}^{K}$ with $\epsilon>>0$ there exists an $\epsilon^{\prime} \in \mathbf{R}^{K}$ with $\epsilon^{\prime}>>0$ such that, for any $U \in \mathcal{D}$ and $x, y \in X$ with $x \succ_{U} y$, we have $x \succ_{U^{*}} y$ for some $U^{*} \in \mathcal{D}$ with $U^{*}(x)<<U(x)-\epsilon^{*}$ and $U^{*}(y)>>U(y)-\epsilon$.

Suppose $\epsilon \in \mathbf{R}^{K}$ with $\epsilon>>0$. Since $K$ is finite, there is a smallest component of $\epsilon$, say $\delta \in \mathbf{R}$. Define $\epsilon^{\prime} \in \mathbf{R}^{K}$ by $\epsilon_{k}^{\prime}=\delta / 4$ for each $k \in K$. Obviously, $\epsilon^{\prime}>>0$. Consider any $U \in \mathcal{D}$ and $x, y \in X$ with $x \succ_{U} y$. Define $a \in \mathbf{R}^{K}$ by $a_{k}=\delta / 2$ for all $k \in K$. By universal domain, the profile $U^{*}$ defined by $U^{*}(z)=U(z)-a$ for all $z \in X$ belongs to $\mathcal{D}$. By our assumption of inter-aspect non-comparable cardinal information, $\succ_{U^{*}}=\succ_{U}$, whence $x \succ_{U^{*}} y$. Finally, by $\epsilon^{\prime}<<a$ we have $U^{*}(x)<<U(x)-\epsilon^{*}$, and by $a<<\epsilon$ we have $U^{*}(y)>>U(y)-\epsilon$, proving (PC).

As $F$ satisfies (PC), as well as universal domain, independence of irrelevant alternatives and global unanimity respectance, the weak welfarism theorem (see Roberts 1980 and Hammond 1996) applies. Its conclusion can be states as follows: there exists a continuous function $W: \mathbf{R}^{K} \rightarrow \mathbf{R}$, increasing with an increase in each argument, such that

$$
W(U(x))>W(U(y)) \Leftrightarrow x \succ_{U} y, \text { for all } x, y \in X \text { and } U \in \mathcal{D} .
$$

In particular, as $x \succ_{U} y \Rightarrow x \succ_{U} y$ (see Lemma 1 in Roberts 1980),

$$
W(U(x))>W(U(y)) \Rightarrow x \succ_{U} y, \text { for all } x, y \in X \text { and } U \in \mathcal{D} .
$$


3. If $\mathcal{A}$ is the singleton $\{K\}$, we are finished since $K$ is dictatorial by (7). Now suppose $|\mathcal{A}| \geq 2 .{ }^{21}$ I will apply Theorem 2 in Khmelnitskaya and Weymark (2000) to the ordering induced by $W$, i.e. to the ordering $R$ on $\mathbf{R}^{K}$ given by

$$
u R v \Leftrightarrow W(u) \geq W(v), \text { for all } u, v \in \mathbf{R}^{K} .
$$

To do so, I first show that $R$ satisfies the following condition (of invariance under cardinal aspect-dependent transformations):

(**) for all $u, u^{*}, v, v^{*} \in \mathbf{R}^{K}$, we have $u R v \Leftrightarrow u^{*} R v^{*}$ if $u^{*}=\phi(u)$ and $v^{*}=\phi(v)$ for some family $\phi=\left(\phi_{k}\right)_{k \in K}$ of increasing affine transformations such that $\phi_{k}=\phi_{l}$ for any issues $k, l$ from the same aspect $A \in A$.

Let $u, u^{*}, v, v^{*}, \phi$ be as specified. I only show that $u^{*} R v^{*} \Rightarrow u R v$, since the opposite implication is analogous. Suppose for a contradiction that not $u R v$. By $|X| \geq 3$ there exist distinct states $x, y \in X$. By universal domain, $\mathcal{D}$ contains a profile $U: X \rightarrow \mathbf{R}^{K}$ with $U(x)=u$ and $U(y)=v$. Since not $u R v$, we have not $U(x) R U(y)$, hence by $(8) W(U(y))>W(U(x))$, and so by (6) $y \succ_{U} x$. So, by $\left(^{*}\right), y \succ \succ_{U^{*}} x$, where $U^{*}$ is the transformed profile $\phi \circ U$. Again by (6), $W\left(U^{*}(y)\right)>W\left(U^{*}(x)\right)$, whence by (8) we have not $U^{*}(x) R U^{*}(y)$, i.e. not $u^{*} R v^{*}$, as desired.

Since $R$ satisfies (**), is continuous (as $W$ is continuous), and is weakly Paretian (as $W$ is increasing with an increase in each argument), Khmelnitskaya and Weymark's Theorem 2 applies to $R$, whence there exists and aspect $A \in \mathcal{A}$ and a continuous and weakly Paretian ordering $R_{A}$ on $\mathbf{R}^{A}$ such that

$$
u R v \Leftrightarrow u_{A} R_{A} v_{A}, \text { for all } u, v \in \mathbf{R}^{K} .
$$

By the continuity of $R_{A}$, Debreu's representation theorem implies the existence of a continuous function $f: \mathbf{R}^{A} \rightarrow \mathbf{R}$ such that

$$
u R_{A} v \Leftrightarrow f(u) \geq f(v), \text { for all } u, v \in \mathbf{R}^{A} .
$$

4. The equivalences (8), (9) and (10) jointly imply that

$$
W(u) \geq W(v) \Leftrightarrow f\left(u_{A}\right) \geq f\left(v_{A}\right), \text { for all } u, v \in \mathbf{R}^{K} .
$$

This and (7) together imply that

$$
f\left(U_{A}(x)\right)>f\left(U_{A}(y)\right) \Rightarrow x \succ_{U} y, \text { for all } x, y \in X \text { and } U \in \mathcal{D} .
$$

So the aspect $A$ is dictatorial, as desired.

(b) The proof of this part proceeds in two steps.

1. First I show that

$$
u \geq v \Rightarrow f(u) \geq f(v), \text { for all } u, v \in \mathbf{R}^{A} .
$$

\footnotetext{
${ }^{21}$ Khmelnitskaya and Weymark restrict their theorem to the case of a non-singleton partition. In fact, their result would also hold without this restriction.
} 
Let $u, v \in \mathbf{R}^{A}$ satisfy $u \geq v$, and suppose for a contradiction that $f(u)<f(v)$. As $f$ is continuous, there is a neighbourhood $B$ of $u$ such that $f\left(u^{\prime}\right)<f(v)$ for all $u^{\prime} \in B$. As $B$ is a neighbourhood of $u$, there exists a $u^{\prime} \in B$ with $u^{\prime}>>u$. We have $f\left(u^{\prime}\right)<f(v)$, but by $u^{\prime}>>v$ we also have $f\left(u^{\prime}\right)>f(v)$ as $f$ is increasing with an increase in each argument, a contradiction.

2. Now suppose $F$ also satisfies continuity, and let me show that $A$ is strongly dictatorial. As $A$ is dictatorial by part (a), we only need to prove that

$$
f\left(U_{A}(x)\right)=f\left(U_{A}(y)\right) \Rightarrow x \sim_{U} y, \text { for all } x, y \in X \text { and } U \in \mathcal{D} .
$$

Suppose for a contradiction that $x, y \in X$ and $U \in \mathcal{D}$ satisfy $f\left(U_{A}(x)\right)=$ $f\left(U_{A}(y)\right)$ but not $x \sim_{U} y$, say $x \succ_{U} y$. Then, as $F$ is continuous, there exists a profile $\bar{U} \in \mathcal{D}$ such that $x \succeq_{\bar{U}} y$ and

$$
\bar{U}(x) \leq U(x), \bar{U}(y) \geq U(y), \quad \begin{aligned}
& \text { with at least one of these vector } \\
& \text { inequalities strict in each component }
\end{aligned}
$$

Taking subprofiles, it follows that

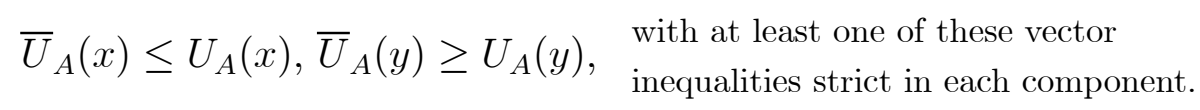

Hence, by 1 . and as $f$ is increasing with an increase in each argument,

$$
f\left(\bar{U}_{A}(x)\right) \leq f\left(U_{A}(x)\right), f\left(\bar{U}_{A}(y)\right) \geq f\left(U_{A}(y)\right), \quad \text { with at least one of these }
$$

As by assumption $f\left(U_{A}(x)\right)=f\left(U_{A}(y)\right)$, it follows that $f\left(\bar{U}_{A}(x)\right)<f\left(\bar{U}_{A}(y)\right)$. So, by part (a), $y \succ_{\bar{U}} x$. This contradicts $x \succ_{\bar{U}} y$.

As an application, we consider the example where welfare, preference and judgment are the only aspects.

Corollary 1 Suppose $K=\left\{\operatorname{Welf}_{i}, \operatorname{Pref}_{i}, \operatorname{Judg}_{i}: i \in N\right\}$ and $\mathcal{A}=\left\{A_{\text {Welf }}, A_{\text {Pref }}, A_{\text {Judg }}\right\}$. If $F$ is as in Theorem 1, one of the following holds:

(i) $A_{\mathrm{Welf}}$ is dictatorial, which implies the weak Pareto principle; if $F$ is also continuous, $A_{\text {Welf }}$ is strongly dictatorial, which implies welfarism.

(ii) $A_{\text {Pref }}$ is dictatorial, which implies preference-unanimity respectance; if $F$ is also continuous, $A_{\text {Pref }}$ is dictatorial, which implies preferencism.

(iii) $A_{\text {Judg }}$ is dictatorial, which implies judgment-unanimity respectance; if $F$ is also continuous, $A_{\mathrm{Judg}}$ is dictatorial, which implies judgmentism.

So, under the assumptions of Corollary 1, no trade-offs between welfares, preferences and judgments are possible. Essentially, one will have to opt either for welfarism, or for preferencism, or for judgmentism, instead of the desired "compromise". 


\section{Theorem 1 vs. Arrow's Theorem: which conditions are relaxable?}

Faced with Theorem 2, what conditions can (should) be relaxed to achieve possibility? Note that the conditions in part (a) of Theorem 2 can be compared with the conditions of (Sen's 1970 cardinal version of) Arrow's Theorem. ${ }^{22}$ As summarised in Table 2, let me try to assess the potential for relaxing different conditions, both in Theorem 2 and in Arrow's Theorem (where I neglect the domain and co-domain conditions ${ }^{23}$ ).

\begin{tabular}{|c|c|c|c|c|}
\hline & $\begin{array}{c}\text { Pareto/ } \\
\text { global unanimity } \\
\text { principle }\end{array}$ & $\begin{array}{c}\text { non-inter- } \\
\text { person/aspect } \\
\text { comparability }\end{array}$ & $\begin{array}{c}\text { cardinal } \\
\text { measurability }\end{array}$ & IIA \\
\hline $\begin{array}{l}\text { Arrow's } \\
\text { Theorem }\end{array}$ & $\begin{array}{l}\text { not compelling } \\
\text { if non-welfare } \\
\text { info. relevant }\end{array}$ & $\begin{array}{c}\text { not compelling } \\
\text { if comparisons } \\
\text { feasible }\end{array}$ & $\begin{array}{l}\text { not compelling } \\
\text { if finer or different } \\
\text { scales feasible }\end{array}$ & $\begin{array}{l}\text { compelling } \\
\text { in constitutive } \\
\text { aggreg. task }\end{array}$ \\
\hline Theorem 2 & $\begin{array}{c}\text { compelling } \\
\text { if } K \text { contains } \\
\text { all relevant issues }\end{array}$ & $\begin{array}{c}\text { compelling } \\
\text { as comparisons } \\
\text { meaningless }\end{array}$ & $\begin{array}{l}\text { not compelling } \\
\text { if finer or different } \\
\text { scales feasible }\end{array}$ & $\begin{array}{l}\text { compelling } \\
\text { in constitutive } \\
\text { aggreg. task }\end{array}$ \\
\hline
\end{tabular}

Table 2: Which conditions of Arrow's Theorem and Theorem 2 are compelling (arguably)?

- While Arrow's weak Pareto principle might be rejected if non-welfare information is deemed relevant, global unanimity respectance is harder to reject once enough issues (possibly non-welfare related ones) are included in $K$.

- While Arrow's exclusion of interpersonal welfare comparisons may be rejected when such comparisons are feasible (such as when an objectively measurable notion of welfare is used), inter-aspect performance comparisons are hardly imaginable and arguably meaningless (provided the aspects in $\mathcal{A}$ are genuinely different, such as when $\left.\mathcal{A}=\left\{A_{\text {Welf }}, A_{\text {Pref }}, A_{\text {Judg }}\right\}\right)$.

- In both theorems, an escape might be sought in dropping the exclusion of non-cardinal information. Possibilities emerge once welfare respectively performance can be measured on a scale finer than cardinality (e.g. a ratio scale or a translation scale), or on an entirely different scale (e.g. List's 2001 zero-line measurability ${ }^{24}$ ).

\footnotetext{
${ }^{22}$ Sen's version of Arrow's Theorem states that every social welfare functional satisfying universal domain, independence of irrelevant alternatives, cardinal inter-personally noncomparable information, and the weak Pareto principle is dictatorial. These conditions are equivalent to those of part (a) of Theorem 2 in the special case of $K=N$ and $\mathcal{A}=\{\{i\}: i \in N\}$.

${ }^{23}$ One might advocate domain restrictions and/or an the incompleteness of social orderings as other, possibly attractive, escape-routes to both impossibility results.

${ }^{24}$ Under zero-line measurability, utility/performance is measurable up to transformations $\phi: \mathbf{R} \rightarrow \mathbf{R}$ that are increasing and satisfy $\phi(0)=0$. Although zero-line measurability
} 
- In both theorems, the condition of independence of irrelevant alternatives (IIA) appears plausible at least when dealing with an aggregation task of the constitutive type (see Section 8). Indeed, to compare two given states $x$ and $y$, any information that determines/constitutes the social goodness of other states $z \in X \backslash\{x, y\}$ appears irrelevant. However, in an aggregation task of the indicative type, information about other states $z \in X \backslash\{x, y\}$ may be relevant to ranking $x$ and $y$, as it may be an indication for the relative goodness of $x$ and $y$. (This is how one may defend the Borda count in the context of indicative aggregation.)

If these arguments are correct, the most promising escape route from the impossibility of Theorem 1 (aside from relaxing domain or co-domain conditions; see footnote 23) is to drop the cardinality restriction. This amounts to seeking for different measurement scales while retaining inter-aspect noncomparability. As mentioned above, the new measurement scale may be finer than or simply unrelated to cardinality. Formally, suppose we have determined for each aspect $A \in \mathcal{A}$ an informational assumption $\equiv_{A}$ (see Section 9) whose measurability restriction is weaker than cardinality (e.g. translation-scale measurability) or unrelated to it (e.g. zero-line measurability). Given the family $\left(\equiv_{A}\right)_{A \in \mathcal{A}}$ of aspect-specific informational assumptions, the informational condition of Theorem 2 can be replaced by that of inter-aspect non-comparable

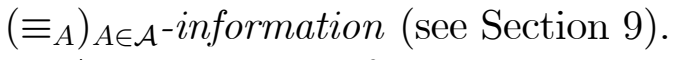

As an example of how this may allow different aspects to be combined and weighed against each other, suppose each aspect $A \in \mathcal{A}$ is translation-scale measurable, i.e., for any $V, V^{*} \in \mathbf{R}^{A}$, we have $V \equiv_{A} V^{*}$ if and only if there exists $a_{A} \in \mathbf{R}$ such that $V_{k}^{*}=a_{A}+V_{k}$ for each issue $k \in A$. Then any evaluation functional of the generalised utilitarian type, given by

$$
x \succeq_{U} y \Leftrightarrow \sum_{k \in K} w_{k} U_{k}(x) \geq \sum_{k \in K} w_{k} U_{k}(y) \text {, for any } x, y \in X, U \in \mathcal{D},
$$

satisfies inter-aspect non-comparable $\left(\equiv_{A}\right)_{A \in \mathcal{A}}$-information, where $w_{k} \geq 0$ represents the weight given to issue $k \in K$. The other conditions of Theorem 2 also hold if the domain is chosen universal and at least one issue $k \in K$ has positive weight $w_{k}$; no aspect $A \in \mathcal{A}$ is dictatorial if the issues with positive weight do not all belong to the same aspect in $\mathcal{A}$.

Finally, a note of clarification is needed. The goal of enabling inter-aspect trade-offs while retaining the formal condition of inter-aspect non-comparability might at first sight appear self-contradictory. How can one possibly weigh noncomparable aspects against each other? The answer is that "non-comparability" refers to a descriptive non-comparability, while "weighing" is a valuational

seems only slightly stronger than ordinal measurability, List (2001) shows the impossibility of Arrow's Theorem disappears once zero-line measurability is introduced (without introducing any comparability). 
(hence normative) exercise. While it appears meaningless to call person $i$ 's welfare "higher" than her preference, it may be meaningful to value her welfare more than her preference. And while it may be meaningless to call the gain of (moral) goodness from $x$ to $y$ in person's $i$ 's judgment "higher" than $j$ 's welfare gain from $x$ to $y$, we could again value the former gain more than the latter. However, a prerequisite for valuing some welfare level more than some preference level is that welfare levels and preference levels are significant; similarly, to weigh a gain in judged-goodnes against a welfare gain the two gains must be significant. It is to ensure such significance that particular forms of aspectmeasurability are required. This is precisely why forms of aspect-measurability can enable valuational comparisons between aspects while retaining descriptive non-comparability.

\section{Conclusion}

In response to arguments that non-welfare information, or more detailed welfare information, may matter to the goodness of social states, I have proposed to analyse social goodness by explicitly including all issues deemed relevant into the model. Potentially relevant issues are, for each person $i, i$ 's welfare $\left(\mathrm{Welf}_{i}\right)$, $i$ 's preference $\left(\operatorname{Pref}_{i}\right), i$ 's judgment $\left(\operatorname{Judg}_{i}\right)$, the source of $i$ 's welfare $\left(\mathrm{SoW}_{i}\right)$, the respectance of $i$ 's individual rights, etc. Of course, each of these issues could be split, e.g. Welf ${ }_{i}$ could be split into different welfare types (pleasure, life expectance, ...). Even other issues may be non-person-specific, such as income equality or preservation of nature. Given any set $K$ of issues, a profile is a family $\left(U_{k}\right)_{k \in K}$ of performance functions $U_{k}: X \rightarrow \mathbf{R}$, measuring how well states perform on issues: $U_{\text {Welf }_{i}}(x)$ measures $i$ 's welfare in $x, U_{\text {Pref }_{i}}(x)$ measures $i$ 's preference for $x$, etc.

There is an obvious formal similarity between deriving the goodness of social states as a function of the performance on issues (as done here) and deriving it as a function of individual welfare (as done in standard welfare economics). Indeed, by identifying issues with individuals and performance functions with individual welfare functions, many well-known and powerful results of welfare economics can be reinterpreted as results about aggregating performance functions. This yields, for instance, characterisations of evaluation functionals such as maximising sum-total performance or maximising minimal performance.

After substituting individual welfare functions by performance functions, standard conditions on aggregation rules receive different meanings and may well become or cease to be desirable. For instance, the weak Pareto principle translates into a global unanimity principle that appears less objectionable (if $K$ contains enough issues, such as the individual sources of welfare, which are neglected by weak Paretianism). By contrast, the plausible anonymity condition of "treating everyone equally" translates into a problematic condition of "treating all issues equally"; and even weak forms of inter-individual welfare 
comparisons may translate into problematic forms of inter-issue performance comparisons.

For any aspect, i.e. set of issues $A \subseteq K$, it can be asked whether this aspect is exclusively relevant for social goodness: whether the evaluation functional should be $A$-ist (as defined in Section 5). Examples are welfarism, preferencism and judgmentism, where social goodness is fully given by, respectively, welfare information, preference information, and judgment information. Other exam-

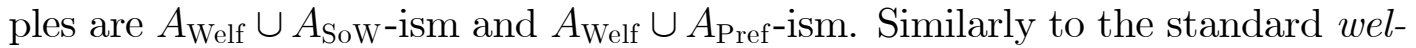
farism theorem, $A$-ism may be derived from the conditions of universal domain, independence of irrelevant alternatives, and $A$-indifference respectance; adding the unproblematic global unanimity principle further yields the $A$-unanimity principle (Theorem 1).

The question of which information is (ir)relevant to social goodness is difficult and partly philosophical. Presumably, answers would depend on the type of aggregation task considered. It may help to distinguish between indicative aggregation tasks, where the profile provides merely evidence on social goodness, and constitutive aggregation tasks, where the profile is what determines/constitutes social goodness. For instance, the welfarist claim that only welfare information can matter refers to constitutive aggregation, and is perfectly compatible with using judgment information in an indicative aggregation task. So welfarism for constitutive aggregation is compatible with judgmentism for indicative aggregation. Judgment information, whose importance for many indicative aggregation tasks is incontestable, may be viewed as irrelevant for constitutive aggregation because, under many but not all notions of goodness, individual judgments are not determinants of (but merely evidence for) social goodness.

If one takes a "purist" position by letting social goodness depend on information of a single type (aspect), obvious candidates are welfarism, preferencism and judgmentism. I have argued that welfarism faces a paternalism charge (by giving people welfare regardless of whether they want it or judge it as morally good), and that preferencism faces the charge of potentially favouring selfish people (whose welfare is represented in their preference) over altruistic people (whose welfare might be underrepresented). One need not consider these objections as defeating; but if one does, one might well opt for judgmentism.

By contrast, a "non-purist" position (more in line with the present model) would be to combine information of different types (aspects), e.g. information on welfare and welfare sources, or information on welfare, preferences and judgments. While this appears attractive, it faces an impossibility result (see Theorem 2): if information is cardinal and inter-aspect non-comparable, and the conditions of universal domain, global unanimity respectance and independence of irrelevant alternatives hold, then some aspect (information type) is dictatorial, i.e. some index for that aspect determines the ranking between all states unless where the index results in a tie (see Section 9). For instance, if welfare and source-of-welfare are the only two aspects, one of them must be 
dictatorial. Yet a "good" combination of aspects would have allowed trade-offs between aspects.

Is this the death of the multi-aspect approach? No, but there appear to be fewer escape-routes than from Arrow's Theorem: global unanimity respectance appears more fundamental than weak Paretianism, and comparisons across aspects appear conceptually more problematic than across individuals. I have argued that this points towards having to drop the cardinality restriction, and seeking for forms of measurability that are finer than cardinality, e.g. ratioscale, translation-scale or even full measurability, or completely different to cardinality, e.g. List's (2001) zero-line measurability. Such alternative measurement scales could open up possibilities of combining information from different aspects. So Theorem 2 can also be read as telling us that, in order to enable attractive multi-aspect aggregation, measuring performance cardinally does not suffice - a finding that might appear interesting to the theoretician and disturbing to the practitioner.

\section{References}

Blackorby C, Bossert W, Donaldson, D (2005) Multi-profile welfarism: a generalization, Social Choice and Welfare 24: 253-267

Blackorby C, Bossert W (2004) Interpersonal comparisons of well-being. In: Weingast B, Wittman, D (eds.) Oxford handbook of political economy, Oxford University Press, Oxford, forthcoming

Bossert W, Weymark J (2004) Utility in social choice. In: Barberà S, Hammond P, Seidl C (eds.) Handbook of utility theory, vol. 2: Extensions, Kluwer, Dordrecht, p. 1099-1177

D'Aspremont C, Gevers L (1977) Equity and the informational basis of collective choice, Review of Economic Studies 44: 199-209

Dietrich F (2004) Judgment Aggregation: (Im)Possibility Theorems, Journal of Economic Theory, forthcoming

Gevers L (1979) On interpresonal comparability and social welfare orderings, Econometrica 47: 75-89

Griffin J (1986) Well-being: its meaning, measurement, and moral importance, Clarendon, Oxford

Hammond PJ (1996) Roberts' weak welfarism theorem: a minor correction, unpublished manuscript, Dept. of Economics, Standford University.

Khmelnitskaya AB (1999) Social welfare orderings for different subgroup utility scales, Discussion Paper \#198, Center for Rationality and Interactive Decision Theory, Hebrew University of Jerusalem

Khmelnitskaya AB, Weymark JA (2000) Social choice with independent subgroup utility scales, Social Choice and Welfare 17: 739-748

List C (2001) A Note on Introducing a 'Zero-Line' of Welfare as an EscapeRoute from Arrow's Theorem, Pacific Economic Review 6(2) (special section 
in honour of Amartya Sen): 223-238

List C, Pettit P (2002) Aggregating Sets of Judgments: An Impossibility Result, Economics and Philosophy 18: 89-110

List C (2004) Multidimensional welfare aggregation, Public Choice 119: 119142

Maskin E (1978) A theorem on utilitarianism, The Review of Economic Studies 45(1): 93-96

Mongin P, d'Aspremont C (1998) Utility theory in ethics. In: Barberà S, Hammond P, Seidl C (eds.) Handbook of utility theory, vol. 1: Principles, Kluwer, Dordrecht, p. 371-481

Roberts K (1995) Valued opinions or opinionated values: the double-aggregation problem. In: Basu K, Patanaik PK, Suzumura K (eds.) Choice, welfare and development: a festschrift in honour of Amartya Sen: 141-165, Oxford University Press

Roemer JE (1996) Theories of distributive justice, Harward University Press, Cambridge, Mass.

Sen A (1970) Interpresonal aggregation and partial comparability, Econometrica 38: 393-409

Sen A (1977a) Social choice theory: a re-examination, Econometrica 45: 53-89

Sen A. (1977b) Rational fools: a critique of the behavioural foundations of economic theory, Philosophy \& Public Affairs 6(4): 317-344. Reprinted in Sen A (ed.) Choice, welfare and measurement, Oxford: Blackwell, 1982

Sen A (1977c) On weighs and measures: informational constraints in social welfare analysis, Econometrica 45: 1539-1572

Sen A (1979) Utilitarianism and Welfarism, Journal of Philosophy 76(9): 463-489

Sen A (1985) Commodities and capabilities. Amsterdam: North-Holland

Sen A (1987) The standard of living, Cambridge University Press

Summer LW (1996) Welfare, happiness and ethics, Oxford University Press 